\title{
Construction of Grain Price Determinants Analysis Model Based on Structural Vector Autoregressive Model
}

\author{
Shudong Wang $\mathbb{D},{ }^{1,2}$ Man Zhang $\mathbb{D}^{3},{ }^{3}$ Yuanzhuo Wang $\mathbb{D},{ }^{4}$ and Hui Meng $\mathbb{}{ }^{4}$ \\ ${ }^{1}$ College of Economy and Management, Anhui University of Science and Technology, Huainan 232001, Anhui, China \\ ${ }^{2}$ College of Economy and Management, Huainan Union University, Huainan 232001, Anhui, China \\ ${ }^{3}$ College of Finance, University of International Business and Economics, Beijing 100029, China \\ ${ }^{4}$ China Export \& Credit Insurance Corporation, Beijing 100033, China \\ Correspondence should be addressed to Shudong Wang; wangshudong@hnuu.edu.cn
}

Received 9 December 2021; Revised 28 December 2021; Accepted 31 December 2021; Published 19 January 2022

Academic Editor: Sheng Bin

Copyright (c) 2022 Shudong Wang et al. This is an open access article distributed under the Creative Commons Attribution License, which permits unrestricted use, distribution, and reproduction in any medium, provided the original work is properly cited.

\begin{abstract}
In 2020, the sudden global epidemic of novel coronavirus pneumonia (COVID-19) caused abnormal fluctuations in the global grain market and posed severe challenges to world grain security. Therefore, it is very important for countries around the world to analyze the determinants of grain price and put forward corresponding strategies to ensure grain safety. In this paper, we theoretically discussed the relationship between financial liquidity, speculation, and grain price for the first time. Based on the analysis of Fisher's equation, this paper argues that the theoretical basis of grain financialization is closer to the volatility theory of the money market. Then, we employ the structural vector autoregression model (SVAR) to explore the impulse response of grain price to the structural shock of world grain production, demand, financial liquidity, and speculation. Our empirical results show that the effects of financial liquidity and speculation on the grain price are more significant. Meanwhile, grain demand changes caused by the global economy have no significant impact on grain price.
\end{abstract}

\section{Introduction}

The stability of grain prices is considered a key issue for grain security and social stability in many countries. In 2020, the sudden global epidemic of novel coronavirus pneumonia (COVID-19) posed severe challenges to world grain security in many ways. In order to control the spread of COVID-19, all countries around the world took strict isolation measures, which affected the global grain supply system. Secondly, the global economic recession caused by COVID-19 reduced the purchasing power of low-income people. Additionally, the quantitative easing of the US dollar leads to the devaluation of the US dollar and some hot money going into the international grain market for speculation, which caused abnormal fluctuations in the global grain market. Therefore, it is crucial for countries around the world to analyze the determinants of grain price and put forward corresponding strategies to ensure grain safety, especially in the period of major global crisis.
Traditionally, it was widely believed that the fluctuations in international grain prices were mostly determined by global grain supply and demand. However, after entering the 21st century, with the rapid development of international financial markets, the correlation between the global grain market and money market, foreign exchange market, futures, and other derivatives markets had significantly strengthened. After the GFC (Global Finance Crisis), in particular, the quantitative easing (QE) measures implemented by the USA and some developed countries resulted in excess liquidity in international capital markets. A large amount of speculative capital flowed into the international grain futures market and other derivatives markets, resulting in large fluctuations in international grain prices. This phenomenon of grain prices deviating from traditional supply and demand is called grain financialization.

Under the influence of grain financialization, the fastgrowing grain derivatives market has increasingly dominated the spot market by virtue of its price discovery 
function. The uncertain factors of derivatives, such as information asymmetry, frequent use of leverage, and increased speculative funds, led to an increase in the frequency and magnitude of fluctuations in international grain prices. At the same time, financial variables such as money supply, interest rates, and exchange rates have gradually replaced the traditional decision-making role of grain supply and demand.

The phenomenon of grain financialization is based on a unique theoretical analysis mechanism. The traditional labor theory of value, supply and demand theory, futures price theory, and cobweb theory are not applicable to food financialization. This paper argues that the theoretical basis of grain financialization is closer to the volatility theory of money market. In combination with Fisher's equation, if the price of an agricultural product is $\mathrm{P}$, the velocity of money $\mathrm{V}$ remains unchanged in a certain period, and it is assumed that the total output of agricultural product $Q$ also remains relatively stable. When the monetary quantity $M$ of the futures and spot markets of the agricultural product changes, it will inevitably lead to the change of the price $\mathrm{Y}$ of the agricultural product. With the acceleration of grain financialization, the relationship between grain price and financial market is getting closer and closer. Economic cycle changes, monetary policy adjustment, and speculative factors will all cause fluctuations in the money market. The excess liquidity caused by the overissuance of money will be transmitted to the agricultural futures market, and then the price of agricultural products in the spot market will fluctuate greatly.

Many types of research were carried out on the increased fluctuation of international grain prices under grain financialization. Historically, the agricultural commodity market has long been segmented from major financial markets [1]. However, with the rapid development of the grain and livestock futures markets, effects of financialization on grain prices began to appear $[2,3]$. In addition to traditional supply and demand, the rise in international commodity prices since the GFC was often the result of excess liquidity and financial capital flowing into commodity markets [4]. If the performance of traders in financial institutions is measured by a commodity index, the correlation between the stock market and the commodities would be positively related to the commodity positions of such institutions [5]. By examining the correlation between the S.P. 500 Index, the MSCI Index, and the international food price fluctuations, international food price fluctuations were negatively related to the US dollar index but positively related to international crude oil price fluctuations [6]. Bruno et al. have shown that the world business cycle and the intensity of financial speculation are important driving forces that affect the coordinated movement of food and financial markets. This driving force has a long-lasting impact on the volatility between agricultural and stock market returns; when the world business cycle is depressed or financial market uncertainty increases, in particular, the correlation between the returns of commodity markets and the stock market positions is significantly positive [7].
The global excess liquidity, the rapid development of the derivatives market, and the influx of speculative capital have promoted the trend of grain financialization, resulting in a more complex decision-making mechanism of international grain prices [8]. Excessive US dollar liquidity and increased speculative activities lead to sharp fluctuations in international grain prices and accelerate the process of grain financialization; grain financialization is also the process of grain dollarization $[9,10]$. The Fed's excessive quantitative easing measures have largely expanded speculative capital, which has a direct impact on the grain futures market and strengthened the phenomenon of grain financialization $[11,12]$. Li et al. adopted the GARCH model and found that the fluctuation of international grain price had obvious aggregation and asymmetry; that is, the fluctuation of grain price caused by good news of rising grain price was greater than that caused by bad news of falling grain price [13]. Li believes that grain and other bulk commodities are increasingly financialized, and the sharp price fluctuations of grain derivatives market are the main manifestations [14]. The grain financialization will lead to the risk of grain price volatility and increase the risk of inflation and income imbalance, resulting in a food financial crisis and other adverse effects $[15,16]$.

In this paper, we analyzed the supply, demand, and price data in the global grain market and found that the supplydemand gaps of 4 major grains (wheat, rice, corn, and soybean) in recent years were not sufficient to explain the sharp fluctuation of their price. We select wheat, rice, corn, and soybean as the representatives of the main grains, mainly because these four grains are in greater global demand and a wider range of demand. This is the general practice of the Food and Agriculture Organization of the United Nations. Then, we systematically discussed the influence mechanism of capital speculation and financial liquidity on global grain prices for the first time. Finally, we first employ the structural vector autoregression model (SVAR) to explore the impulse response of grain price to the structural shock of world grain production, demand, the real effective exchange rate of the US dollar, and grain speculation. Our empirical results show that financial liquidity and world grain production have a significant impact on international grain price, followed by international capital speculation. Meanwhile, global demand has a negligible effect on grain pricing.

\section{Grain Price Trend and Its Determinants}

Traditionally, it was widely believed that the fluctuations in international grain prices were mostly determined by global grain supply and demand. However, this situation has changed in recent years. Under the background of financialization, the traditional grain supply and demand is no longer the whole reason influencing the international grain prices. By observing the trend of the international grain price and the global macroeconomy in recent years, it is not difficult to find that there is a close relationship between the sharp fluctuation of international grain prices and the 
speculation of the grain futures market, as well as the financial liquidity generated by the quantitative easing monetary policy launched by the Federal Reserve.

\subsection{Sharp Fluctuation of International Grain Prices in Recent} Years. By surveying the monthly average price data of the four major grains from 1992 to 2019 (see Figure 1), we find that the prices of the four major grains have fluctuated sharply since 2000. On the one hand, the fluctuation frequency of international grain prices increased significantly. The prices of wheat, corn, and soybean all reached periodic peaks in 2008, 2011,2012, and 2014, while the price of rice was at a historical high in 2008. On the other hand, the fluctuation ranges of international grain prices increased significantly. The annual price peaks of the four major grains in 2008, 2011, 2012, and 2014 all exceeded the corresponding grain prices during the fourth global grain price peak between 1995 and 1996.

The above analysis shows that since 2000, for the four major grains, the fluctuation range of the difference between production and demand in the proportion of total output has fallen significantly. For grain price peaks in 2008 and 2011, wheat, corn, and rice showed a positive supply-demand gap, and soybean had negative supply-demand gap ratios of $-4.43 \%$ and $-7.55 \%$, respectively. For grain price peaks in 2012, only wheat showed a negative supply-demand gap ratio of $-3.22 \%$. For the grain price peak in 2014, all 4 grains had positive supply-demand gaps. This indicates that since 2000, the trend of international grain prices is characterized by a weakening link with the fundamentals of global grain supply and demand. Large fluctuations in international grain prices do not entirely stem from the traditional imbalance between global grain supply and demand.

\subsection{No Obvious Gap between Global Grain Supply and De-} mand in Recent Years. In this paper, we first surveyed the total output and consumption data of four major grains (wheat, corn, rice, and soybeans) from 1992 to 2019 (see Figure 2). In Figure 2, wheat, corn, and rice all had large supply gaps in 2002 and 2003. In 2002, the supply-demand gaps of the three main grains were 34.44 million tons, 20.16 million tons, and 25.46 million tons, respectively. In 2003, the supply-demand gaps of the three main grains were 34.18 million tons, 24.2 million tons, and 22.07 million tons, respectively. Soybeans showed a larger supply gap in 2011, with a shortfall of 18.08 million tons. In other years of Figure 2, the gap between supply and demand of the world's four major grains was relatively small.

In order to reflect the asymmetry between the annual supply and demand of the four staple grains over the past 30 years, we calculate the proportion of the difference between the total global output and the total global consumption in the total global output (see Figure 3). It can be seen that, between 1992 and 2019, the proportion of the difference between output and consumption in the total output of wheat, corn, rice, and soybean fluctuated from $-6.16 \%$ to $5.96 \%,-7.34 \%$ to $4.4 \%,-7.71 \%$ to $2.56 \%$, and $-7.55 \%$ to $8.84 \%$, respectively. Since 2008 , the fluctuated proportion shrank significantly for the four major grains. In particular, the supply and demand of wheat, corn, and rice are basically in a balanced state, and the difference between production and demand in the proportion of the total output fluctuated from $-3.24 \%$ to $5.96 \%,-2.14 \%$ to $4.20 \%$, and $-0.67 \%$ to $2.56 \%$, respectively. According to the above analysis, we found that there is no obvious gap between supply and demand in the global grain market reflected by the four major grains. In most years, the total output of wheat, corn, and rice is even higher than total domestic consumption.

\subsection{Speculative Forces in International Capital Markets} Pushed Up International Grain Price after GFC. According to the statistics of the International Grain and Agriculture Organization (FAO), total world grain production increased from 2.01 billion tons in 2006 to 2.11 billion tons in 2007, an increase of $4.9 \%$. However, with the rapid growth in biofuel, grain demand also steadily increased. As a result, global grain stocks at the end of the quarter dropped from 427 million tons in 2006 to 408 million tons at the end of 2007. Although the stock was still in surplus at the end of the season, concerns about grain supply shortages led to grain export restriction policy in some countries, such as Argentina, India, Pakistan, and Russia. The policy shifts in major grain exporters also attracted speculative money into the international grain derivative market. The total position of grain futures and options continued to rise within this period (see Figure 4), which led to excessive trade and further pushed up grain prices. Against the backdrop of steady growth in total grain production, the rising trend of the four major grain prices continued until the second quarter of 2008 and reached phase peaks. According to IMF data, the monthly price of wheat on the international market rose from $\$ 172.6 /$ ton in January 2007 to an all-time high of \$403.8/ton in March 2008 , an increase of $234 \%$. Meanwhile, the monthly price of rice increased from $\$ 313.5 /$ ton in January 2007 to a record high of $\$ 1015.2 /$ ton in April 2008, an increase of $324 \%$.

\subsection{Excess Financial Liquidity Generated by QE Leads to} Drastic Volatility in International Grain Prices. Stimulated by high grain prices since 2007, major grainproducing countries made efforts to increase production in 2008, and global grain production reached about 2.164 billion tons, an increase of $2.46 \%$. The increase in grain production drove grain prices down from their historic highs. For instance, according to USDA, the spot price of wheat fell from $\$ 7.78$ /bushel on July 7,2008 , to $\$ 4.23 /$ bushel on December 9, 2008, a decline of $45.6 \%$. However, after the outbreak of the subprime mortgage crisis which dragged the US economy into crisis, grain price significantly rebounded. On one hand, prices of commodities such as grain, which are priced in dollars, rebounded again as a result of the dollar's decline. On the other hand, the QEs, which were launched by the US Federal Reserve three times (see Table 1), released a large amount of financial liquidity into the grain futures market. The consequent increase in speculation caused dramatic fluctuations in international grain price. 

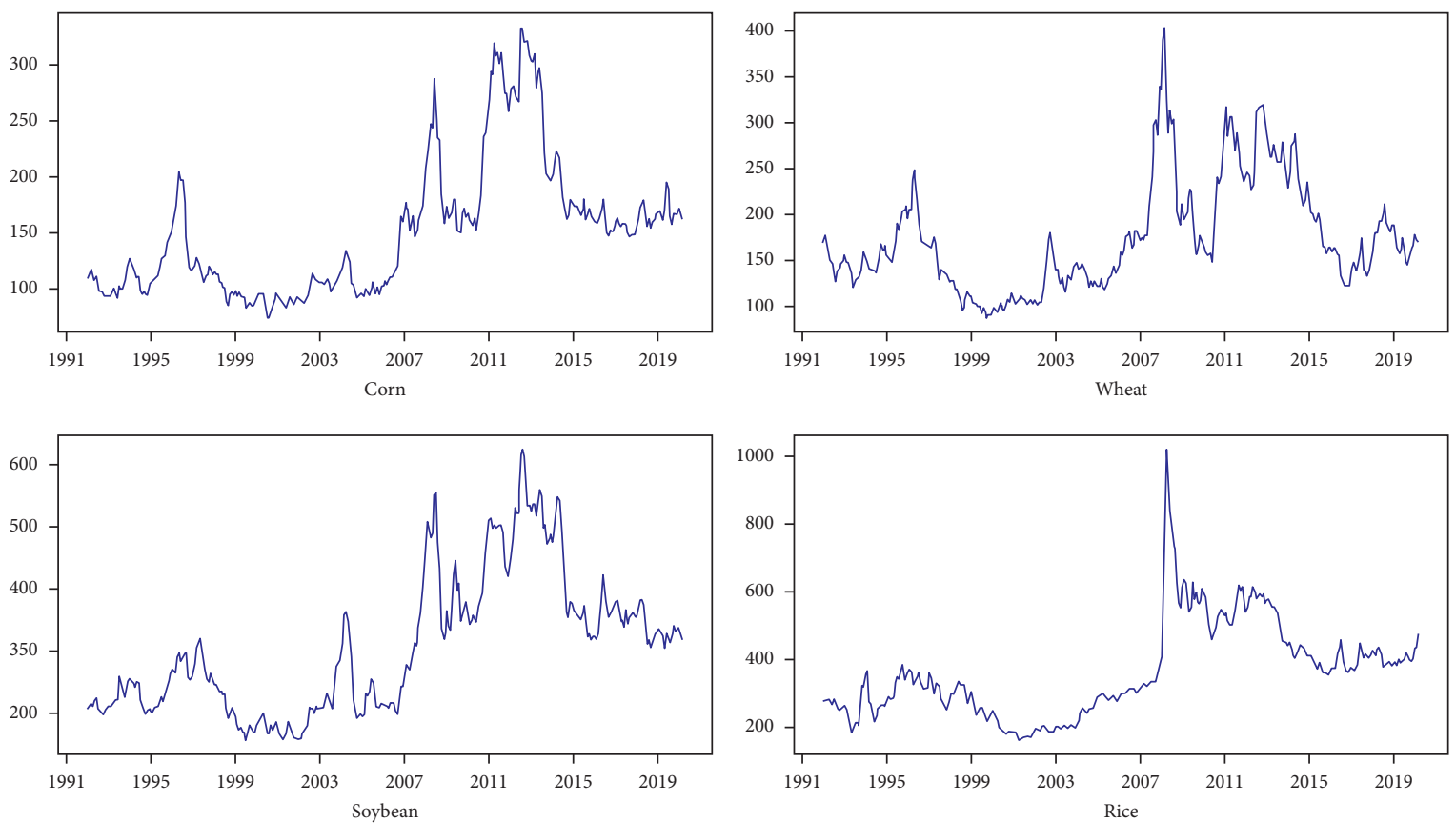

FIGURE 1: The price fluctuations of the four major staple grains in the international market from 1992 to 2019. Following IMF, the authors select the FOB price of US No. 1 hard red winter wheat Gulf of Mexico, the US No. 2 yellow corn in the Gulf of Mexico, 5 percent broken milled white rice from Thailand, and the No. 2 soybean futures contract price of the Chicago Board of Trade in the United States. Unit: USD/ ton.
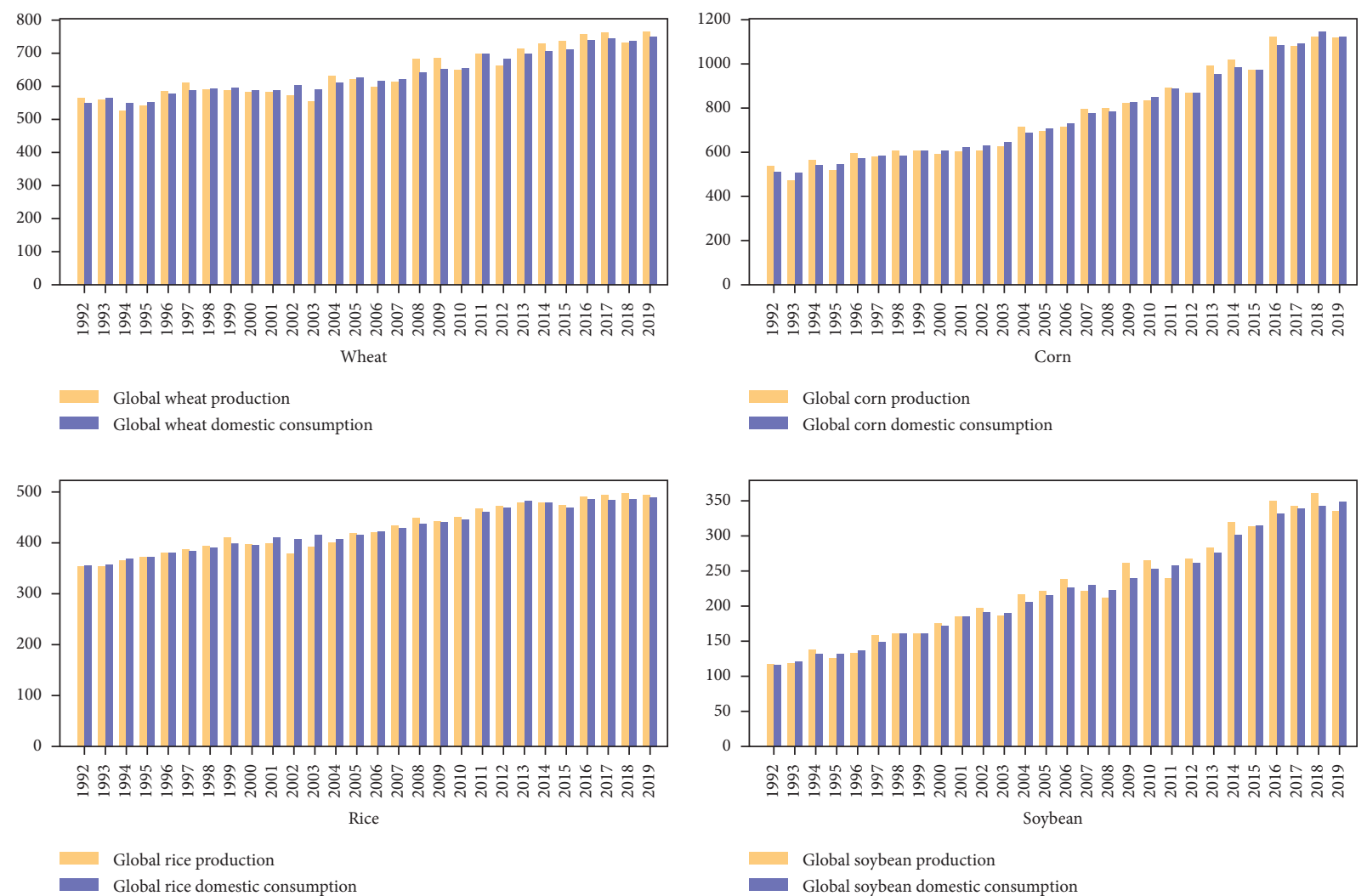

Figure 2: Total output and consumption of the world's four major staple grains from 1992 to 2019 (million tons). 


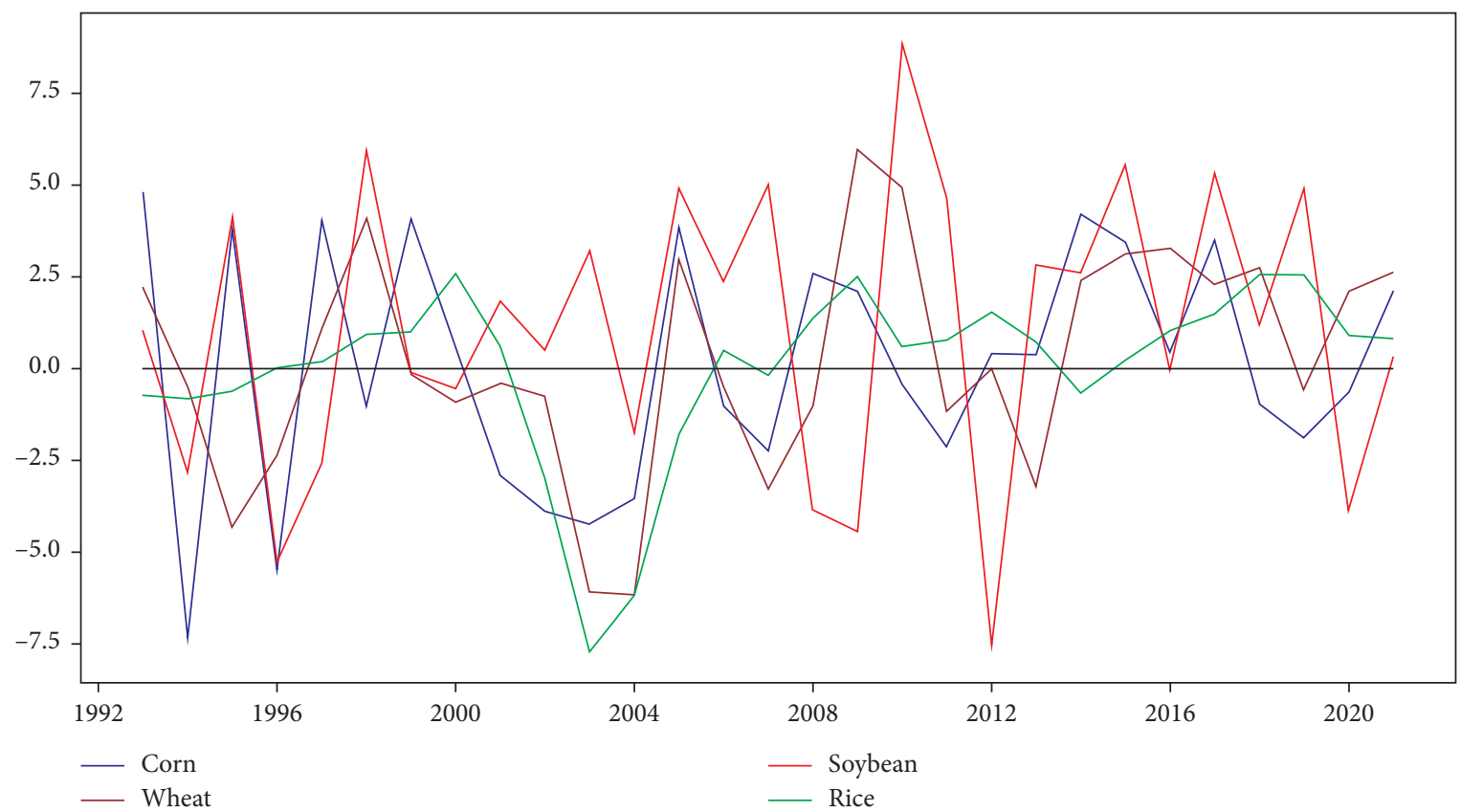

FIgURE 3: Supply-demand gap of the world's four staple grains from 1992 to 2019 (as a percentage of total production).

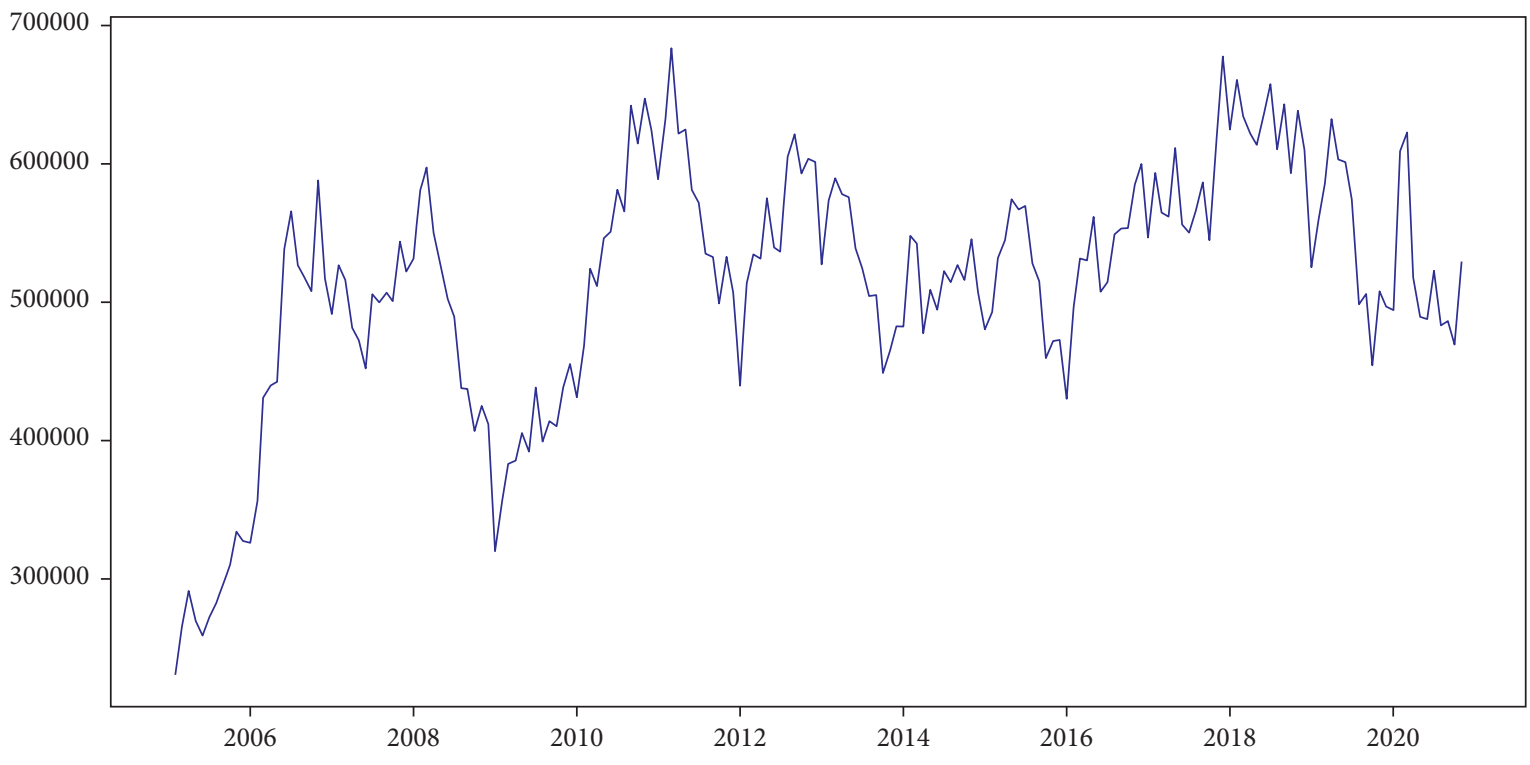

FIGURE 4: Total position of CBOT wheat futures and options.

Take wheat as an example; the total position of CBOT wheat futures and options during QE1 increased rapidly from 313,400 at the beginning of December 2008 to 460,000 at the beginning of June 2009 (see Figure 4), and the average daily wheat spot price rose from $\$ 4.22 /$ bushel to $\$ 6.28$ / bushel during the same period, an increase of $48.5 \%$. During $\mathrm{QE2}$, CBOT wheat futures and options trading reached an all-time high of 722,900 contracts, while the wheat spot prices reached $\$ 9.76 /$ bushel on February 10, 2011. During QE3, the wheat spot price peaked at $\$ 9.69 /$ bushel on September 17, 2012.

\section{Methodology and Data}

3.1. Methodology. By imposing long- or short-term restrictions on the economic model, the structural vector autoregressive (SVAR) model can identify the sources of different economic shocks and improve the fitting degree of the model to economic variables. By employing SVAR model, we explore the impulse responses of grain prices to the shock of global grain supply, demand, speculation, and financial liquidity.

The form of the SVAR model is as follows: 
TABLE 1: The Fed's three quantitative easing monetary policy schedules.

\begin{tabular}{lcc}
\hline Time period & Measurements \\
QE1 $\begin{array}{c}\text { Dec. 2008-March } \\
2010\end{array}$ & Purchased a total of \$1.25 trillion in institutional MBS and \$300 billion in Treasury bonds. \\
QE2 Nov. 2010-June 2011 & $\begin{array}{c}\text { A total of \$600 billion in Treasury bonds were purchased. } \\
\text { Purchase of \$40 billion of MBS per month with distortion operations (OT) since Sep. 2012. Purchase of \$45 } \\
\text { QE3 Sep. 2012-Oct. 2014 }\end{array}$ & $\begin{array}{c}\text { billion in Treasury bonds since Dec. 2012. The purchase scale started to reduce in December 2013 and ended in } \\
\text { October 2014. }\end{array}$ \\
\hline
\end{tabular}

$$
\Gamma_{0}=\alpha_{t}+\sum_{i=1}^{p} \Gamma_{i} x_{t-1}+\varepsilon_{t},
$$

where $x_{t}=\left(x_{1 t}, x_{2 t}, x_{3 t}, x_{4 t}, x_{5 t}\right)^{T}$ is a $5 \times 1$ vector, $\alpha_{t}$ is a constant vector, $\varepsilon_{t}$ denotes error vector, and $p$ is the lagged order. If the matrix $\Gamma_{0}$ is invertible, we can get its reduced form:

$$
x_{t}=\Gamma_{0}^{-1} \alpha_{t}+\sum_{i=1}^{p} \Gamma_{0}^{-1} \Gamma_{i} x_{t-i}+u_{t},
$$

where $u_{t}=\Gamma_{0}{ }^{-1} \varepsilon_{t}$. In order to identify the above model, we need to impose identifying assumptions and obtain a recursively structural model. Let $x_{t}=$ (Prodction $_{t}$, Demand $_{t}$, Exchange $_{t}$, Speculation $_{t}$, Price $\left._{t}\right)^{T}$, where Prodction $t$ represents the global supply of grains in period $t$, De mand $t$ represents the global grain demand in

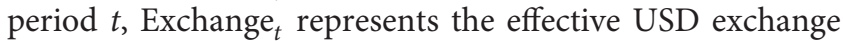

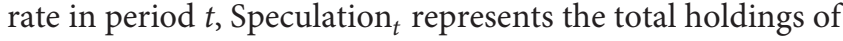
futures and options of each grain on the CBOT, and Price $t_{t}$ represents the international spot price of each staple grain during period $t$.

Based on the short-term relationship between variables, the recursive restrictions in this structural model assume the following. First, considering the seasonality of crop planting, the global grain supply Prodction $_{t}$ will not respond to a shift in demand for grain Demand $t$ within the same month. Second, as an effective substitute for international financial liquidity, fluctuations in the real effective exchange rate of the US dollar Exchange E $_{t}$ will have no impact on the global grain supply and demand in the short term. Third, the fluctuation of Speculation $t_{t}$ will not affect global grain supply and demand in the same month, as well as the real effective exchange rate of the US dollar. Finally, the change of international grain price Price ${ }_{t}$ does not influence the international capital speculation, the real effective exchange rate of US dollar, and the global grain supply and demand in the same month. Under the above restrictions, $\Gamma_{0}$ is a lower triangle matrix; that is,

$$
=\left(\begin{array}{ccccc}
1 & 0 & 0 & 0 & 0 \\
\tau_{21} & 1 & 0 & 0 & 0 \\
\tau_{31} & \tau_{32} & 1 & 0 & 0 \\
\tau_{41} & \tau_{42} & \tau_{43} & 1 & 0 \\
\tau_{51} & \tau_{52} & \tau_{53} & \tau_{54} & 1
\end{array}\right)\left(\begin{array}{c}
\varepsilon_{1 t} \\
\varepsilon_{2 t} \\
\varepsilon_{3 t} \\
\varepsilon_{4 t} \\
\varepsilon_{5 t}
\end{array}\right) .
$$

Then, the SVAR model is a just-identified model.

3.2. Variable Selection. In this work, we discuss the actual effect of grain supply, demand, financial liquidity, and speculation on international grain price fluctuation. According to the previous theoretical analysis, the effective exchange rate of the US dollar is used to reflect the fluctuation of financial liquidity. Therefore, monthly average data of the real effective US dollar exchange rate index is used as the substitution variable of financial liquidity. The change of aggregate gross position in grain futures and options contracts can reflect the change of international capital speculation. Therefore, the monthly average position of grain futures and options contracts for four major grains (wheat, corn, rice, and soybean) in the Chicago Stock Exchange $(\mathrm{CBOT})$ is used as a substitute variable for the speculation.

Global grain production is mainly affected by planting options of farmers and weather conditions. Meanwhile, the demand for grain is mainly affected by the situation of the global economy. Hence, USDA crop yield forecast data for major countries and the world is selected as substitute data of the global grain supply, while the Baltic Dry Bulk Index is selected as a representative indicator of global economic activity and global grain demand.

Finally, as for the international grain price, we select the monthly data of the international spot price of wheat, corn, rice, and soybean. Considering the availability of data, the period of all data is July 2002 to August 2020. The main sources of data in this paper are USDA, CBOT, the World Clearing Bank, and the Wind database.

3.3. Data Stationarity Test. All the data applied here are monthly data, from $2002 / 7$ to $2020 / 8$. Before the empirical analysis, we take the log change of all the data. In Table 2 of the data stability test, the results of the ADF, PP, and KPSS stability test showed that the first-order logarithmic difference of almost all data was stable at $1 \%$ of the significant level, while only the KPSS level test of the real effective exchange rate index is not stable at the significance level of $10 \%$.

\section{Empirical Analysis}

The impulse response function measures the effect of a onestandard-deviation random perturbation of each variable on a specified variable. The function can intuitively describe the dynamic interaction and effect between variables and judge 
TABLE 2: Data stability test.

\begin{tabular}{|c|c|c|c|c|}
\hline Variables & ADF test & PP test & KPSS level & KPSS trend \\
\hline Production (corn) & $-6.68^{* * *}$ & $-189.63^{* * *}$ & 0.017 & 0.018 \\
\hline Production (wheat) & $-5.48^{* * *}$ & $-208^{* * *}$ & 0.028 & 0.027 \\
\hline Production (soybean) & $-6.47^{* * *}$ & $-203.97^{* * *}$ & 0.023 & 0.023 \\
\hline Production (rice) & $-7.82^{* * *}$ & $-211.12^{* * *}$ & 0.047 & 0.033 \\
\hline Demand & $-7.16^{* * *}$ & $-187.24^{* * *}$ & 0.053 & 0.046 \\
\hline Exchange & $-5.61^{* * *}$ & $-132.53^{* * *}$ & $0.38^{*}$ & 0.042 \\
\hline Inventory (corn) & $-6.32^{* * *}$ & $-132.53^{* * *}$ & 0.13 & 0.033 \\
\hline Inventory (wheat) & $-6.66^{* * *}$ & $-237.54^{* * *}$ & 0.32 & 0.042 \\
\hline Inventory (soybean) & $-6.36^{* * *}$ & $-203.27^{* * *}$ & 0.059 & 0.017 \\
\hline Inventory (rice) & $-4.57^{* * *}$ & $-255.45^{* * *}$ & 0.059 & 0.041 \\
\hline Price (corn) & $-6.54^{* * *}$ & $-176.08^{* * *}$ & 0.17 & 0.045 \\
\hline Price (wheat) & $-5.19^{* * *}$ & $-165.06^{* * *}$ & 0.10 & 0.042 \\
\hline Price (soybean) & $-6.39^{* * *}$ & $-126.04^{* * *}$ & 0.13 & 0.029 \\
\hline Price (rice) & $-6.86^{* * *}$ & $-120.84^{* * *}$ & 0.12 & 0.053 \\
\hline
\end{tabular}

$*{ }^{* *}$, and ${ }^{* * *}$ indicate the significance at the statistical levels of $10 \%, 5 \%$, and $1 \%$, respectively.

the time lag relationship between variables from dynamic reactions. Figures 5-8, respectively, describe the response trend of four grain prices against shocks in grain production, demand, US dollar effective exchange rate, and holding position of futures and options. The vertical axis represents the side and magnitude of each endogenous variable to the impact response, while the horizontal axis represents the time lag. The solid line represents the pulse response function, and the dotted line represents the plus or minus two standard deviation bands. In terms of duration, 15 periods were selected for analysis in this work.

As shown in Figure 5, an increase in global production of wheat and corn will rapidly lower their market price, after which the impact of global supply on prices will gradually move towards zero in seven months. An increase in soybean supply will have a negative impact on its price, which peaks in the fifth month before it rebounds and gradually moves towards zero. On the contrary, a structural supply shock will first generate a positive impact on rice price before it gradually gets stabilized. Here the rice price responses towards supply shocks are not consistent with general perception. That is probably because the population growth rate of East and Southeast Asia, where the main consumer area of rice is, is higher than rice production growth rate. In addition, despite production growth, restrictions on rice exports by the major producer countries also continuously push up international rice price. Therefore, we may conclude that the reaction of wheat, corn, and soybean prices to yield shocks indicates that the increase in grain supply reduces its price, in line with our conventional understanding.

Figure 6 gives the impulse responses of the four staple grain prices to structural demand shock. We find that all staple grain prices make rapid positive responses in the first month after the global demand shock and then gradually stabilize and tend to zero. Wheat and corn both achieve their largest positive response in the fifth month, while rice and soybean make the largest positive response in the first month. This suggests that a rising grain demand will lead to higher grain prices, in line with the traditional theory of supply and demand. In addition, we find that, different from other commodities such as oil, the global economy has a negligible effect on the four staple grain prices. One explanation is that the fluctuation of global economy will not have a significant impact on global demand for the staple grains, which are daily necessities. Global demand for staple foods depends largely on global population changes and per capita food consumption. Per capita food consumption is less resilient to fluctuations in the global economy.

In Figure 7, we show the impulse response of the grain price to the structural shock of the effective US dollar exchange rate. Given a structural shock of US dollar effective exchange rate, all four staple grain prices respond negatively in the first month and then start to rebound and eventually tend to 0 . The impulse responses of wheat and soybean reach their peak responses in the second month, while rice is in the third month and corn is in the sixth month. This result shows that excessive issuance of US dollars leads to excess financial liquidity, which in turn devalues the US dollar and pushes up grain price.

In Figure 8, after the structural shock of speculation, the price of wheat, corn, and soybean shows positive response quickly; then the range of fluctuation gradually becomes smaller and gradually tends to 0 . The maximum response of corn and wheat price appears in the first month, while soybean price appears in the second month. This indicates that the speculation in wheat, corn, and soybean markets is active, and its effect on price can reach a maximum in a short time. Under the background of grain financialization, the impact of international speculation on grain pricing is increasing. This conclusion supports the view that increasing total derivative positions due to speculation and frequent trade leads to higher grain price. Meanwhile, the hysteretic behavior of speculative shock pushing up rice price is mainly because the derivative market scale of rice is relatively small compared to the other grains. For example, the average position of CBOT rice accounts for only $1 \%$ compared to average CBOT corn position, implying less speculation and slower price response than the other three grains. 

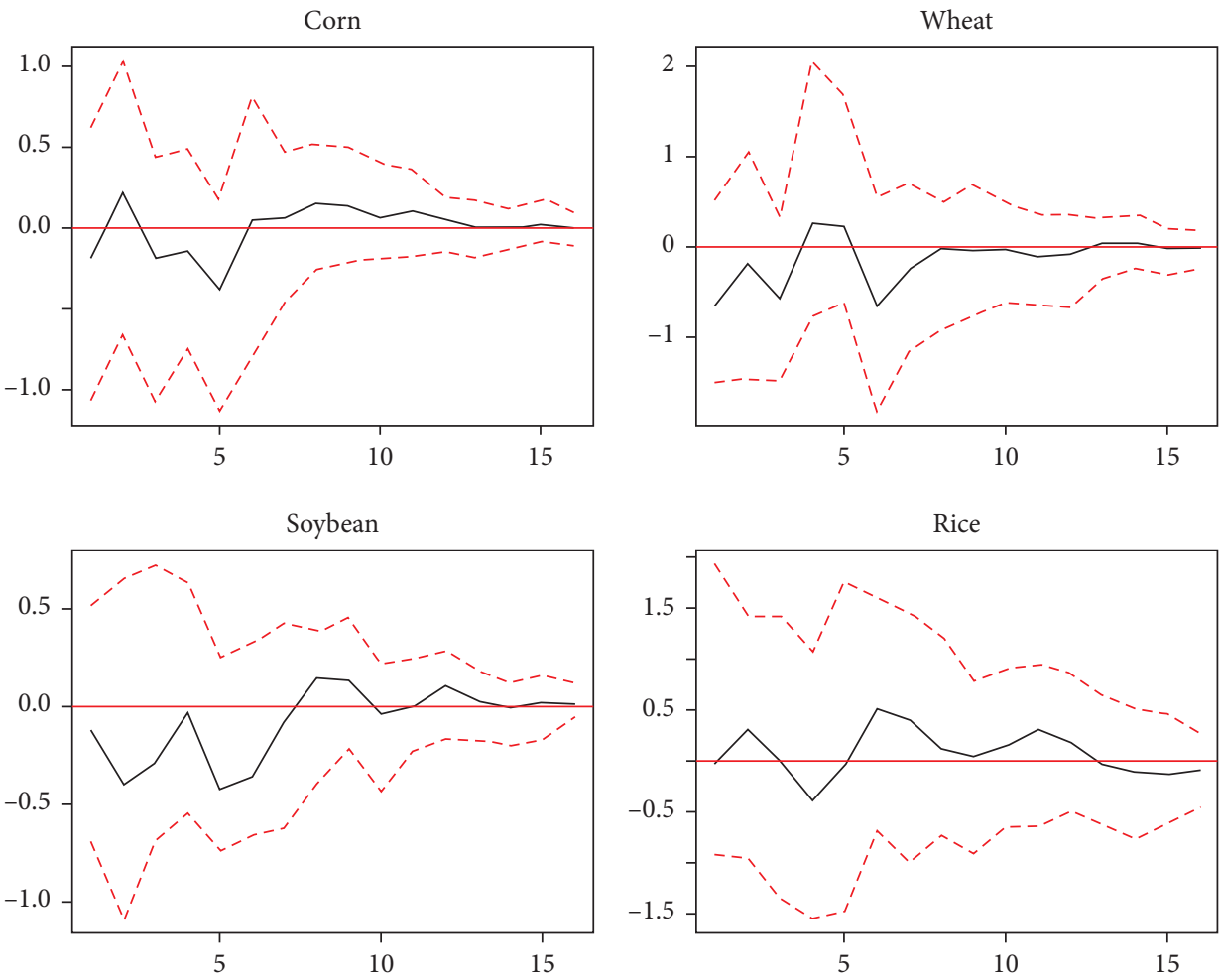

FIgURE 5: Impulse responses of the four staple grain prices to one-standard structural supply shock.
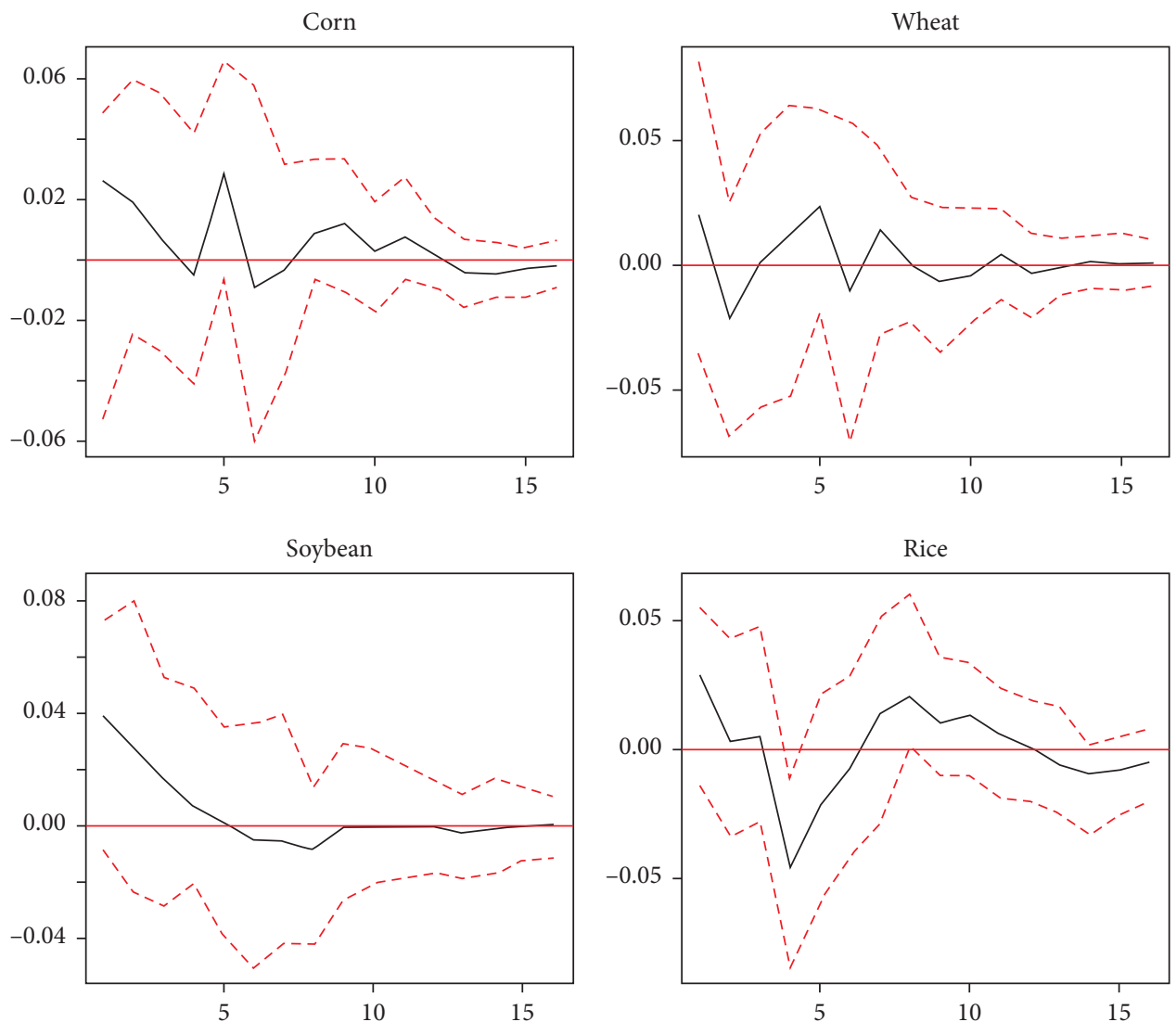

Figure 6: Impulse responses of the four staple grain prices to one-standard structural demand shock. 

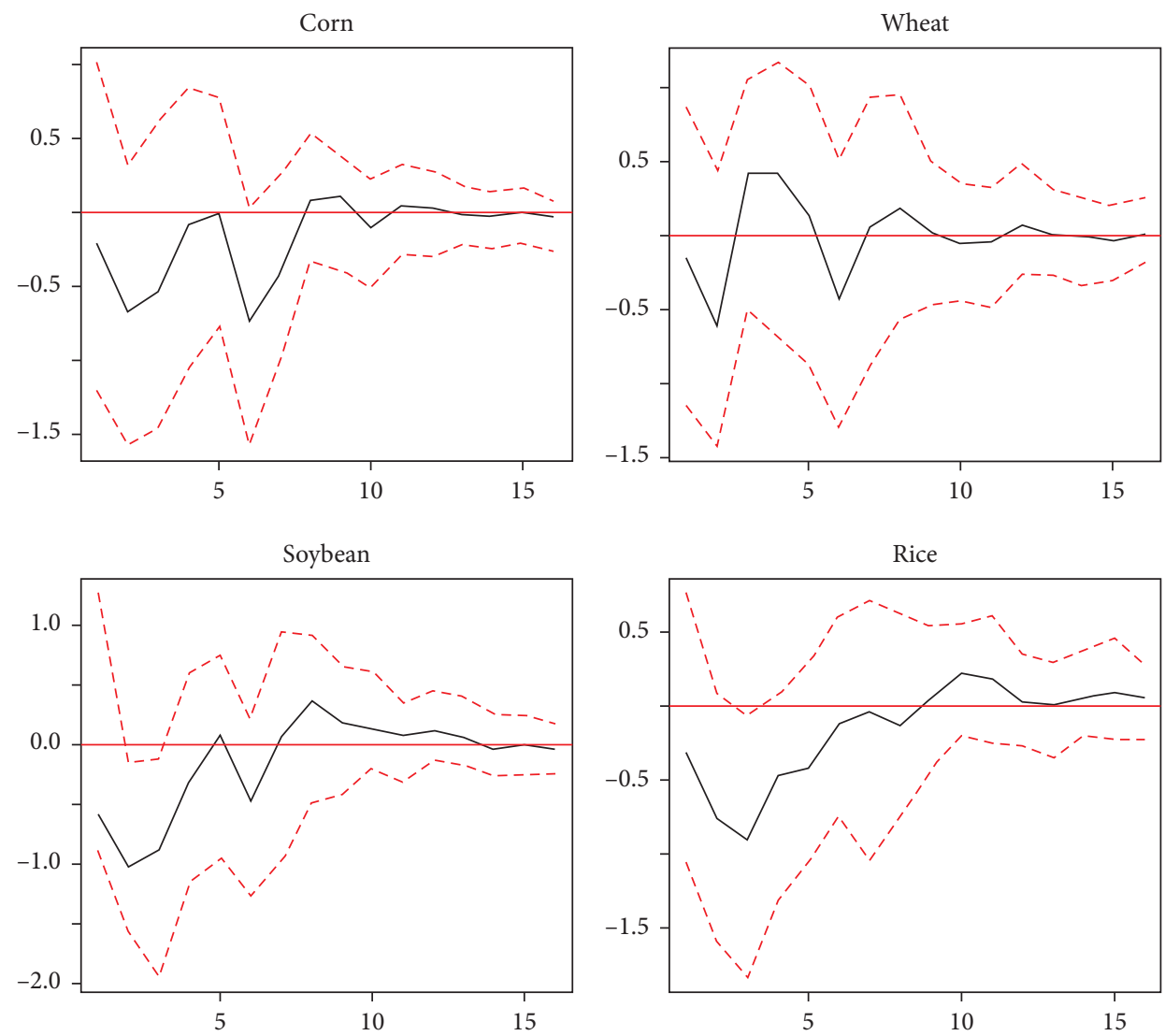

FiguRE 7: Impulse responses of the four staple grain prices to one-standard structural exchange rate shock.
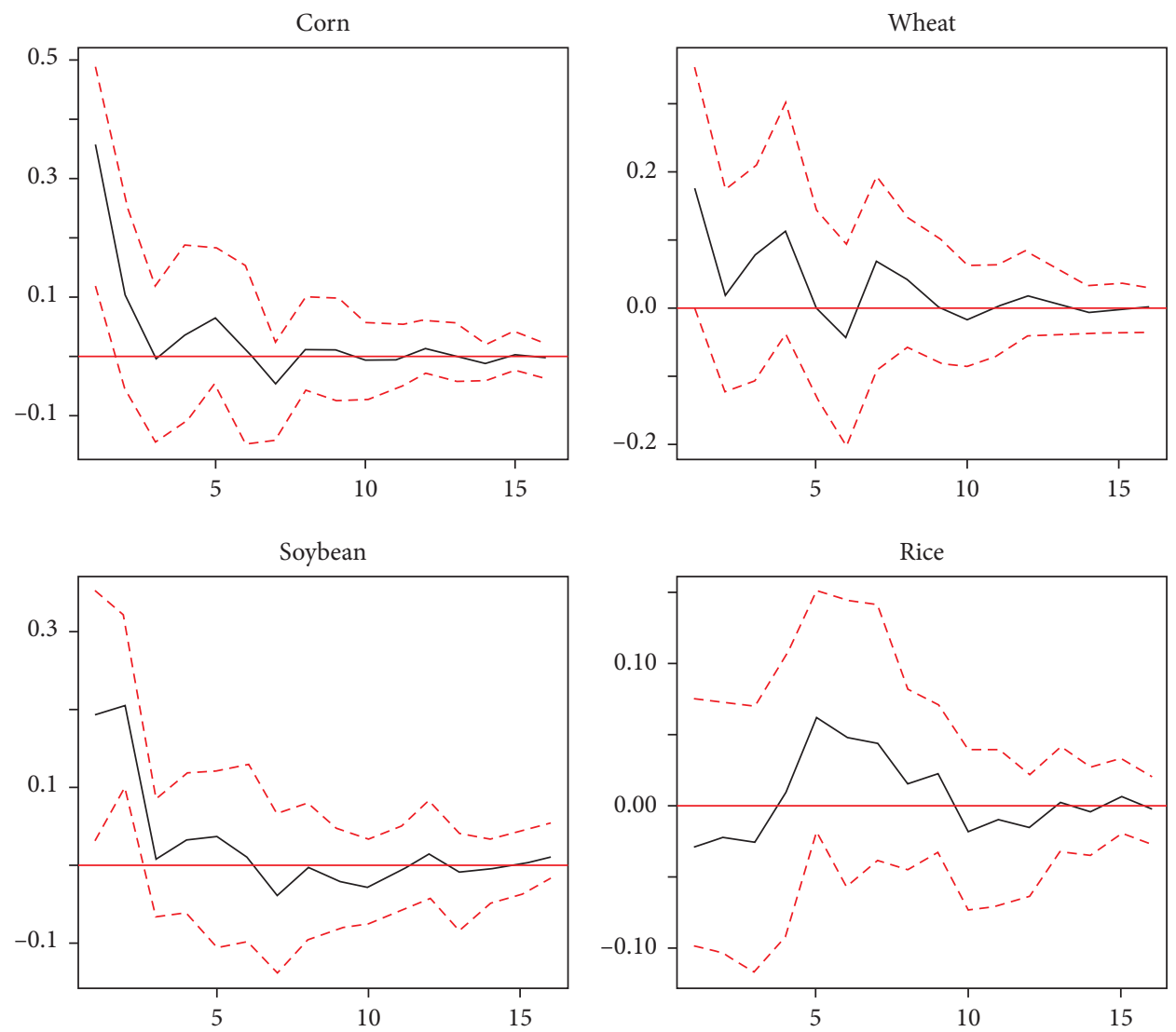

FIGURE 8: Impulse responses of the four staple grain prices to one-standard structural speculation shock. 


\section{Conclusions and Policy Suggestions}

First, we analyze the historical relationship between grain supply, demand, and price and find that the dramatic fluctuation in international grain price is no longer fully explained by the traditional supply-demand theory, especially after GFC. So, we theoretically discussed the detailed relationship between financial liquidity, grain speculation, and price. Then, we selected several variables that might affect grain price and employed the structural vector autoregression model (SVAR) to explore the impulse response of grain price to the structural shock of world grain production, demand, the real effective exchange rate of US dollar, and grain speculation. From the empirical results, we found that financial liquidity and world grain production had a significant negative impact on international grain price, while international capital speculation had a positive but weaker effect. Meanwhile, grain demand changes caused by the global economy had a negligible and positive effect on grain price.

These results showed that, in addition to traditional supply and demand factors, financial liquidity and international capital speculation also had significant impacts on international grain prices in the context of grain financialization. More abundant international financial liquidity or greater international capital speculation power would cause significant rises in international grain prices. According to our conclusion and considering the current excess financial liquidity and growing grain speculation, we suggest that countries around the world should pay more attention to grain financialization. Given the loose monetary environment in the post-COVID-19 period, rising global liquidity and speculation activities may lead to sharp rises and volatility in international grain price and even trigger a grain crisis. Net grain importing and exporting countries can consider hedging the risk of grain price fluctuation through exchange rate instruments. We should strengthen oversight of futures and capital markets, improve the agricultural market information disclosure mechanism and the food security early warning system, release timely and accurate information on supply and demand of key agricultural products and guide market price expectations, and prevent excessive speculation and speculation.

\section{Data Availability}

No data were used to support this study.

\section{Conflicts of Interest}

The authors declare that they have no conflicts of interest.
Yangtze River Delta (Anhui Region)" (sk2020a0691) and "Study on the Development of Green Urbanization in Huaihe Ecological Economic Belt--Taking Huainan City as an Example" (sk2019a0862).

\section{References}

[1] H. Bessembinder, "Systematic risk, hedging pressure, and risk premiums in futures markets," Review of Financial Studies, vol. 5, no. 4, pp. 637-667, 1992.

[2] FAO, GIEWS Country Briefs 9, FAO, Rome, Italy, 2011.

[3] R. J. Myers, "On the costs of food price fluctuations in lowincome countries," Food Policy, vol. 31, no. 4, pp. 288-301, 2006.

[4] M. Nissanke, "Commodity market linkages in the global financial crisis: excess volatility and development impacts," Journal of Development Studies, vol. 48, no. 6, pp. 732-750, 2012.

[5] S. Basak and A. Pavlova, "A model of financialization of commodities," The Journal of Finance, vol. 71, no. 4, pp. 1511-1556, 2016.

[6] K. Matur, N. Kaicker, R. Gaiha, K. Imai, and G. Thapa, "Financialisation of food commodity markets, price surge and volatility : new evidence," Handbook on Food, The University of Manchester, Manchester M13 9PL, UK, pp. 149-176, 2014.

[7] V. Bruno, B. Buyuksahin, and M. Robe, "The financialization of food?" American Journal of Agricultural Economics, vol. 7, pp. 1-22, 2016.

[8] Q. Fan and M. Liu, "The Trend of International Grain Financialization and China's Grain Security Countermeasures," Macroeconomic management, vol. 7, pp. 32-34, 2012.

[9] L. Jia and H. Li, "Financial empire, food hegemony and China's food strategy," Journal of Strategy and Management, vol. 12, pp. 32-34, 2011.

[10] T. Wen, J. Han, and J. Gao, "Grain financialization and security," Theoy Exploration, vol. 5, pp. 82-87, 2014.

[11] X. Huang, "Analysis on the mechanism of international bulk agricultural product price financialization and China's policy choice," International trade, vol. 6, pp. 23-26, 2012.

[12] X. Yang, "Food crisis in arab countries under the framework of the belt and road initiative food security risks," Journal of Arab World Studies, vol. 7, pp. 45-58, 2015.

[13] S. Li, H. Qi, and Q. Fan, "Analysis on the characteristics and causes of international grain price Fluctuation under the trend of grain financialization," Journal of Rural Economics and Technology, vol. 5, pp. 6-9, 2016.

[14] Y. Li, "Food financialization: definition, background and characteristics," Journal of Financial Theory and Practice, vol. 10, pp. 42-45, 2012.

[15] B. Wright and C. Cafiero, "Grain reserves and food security in the Middle East and north africa," Journal of Food Science, vol. 3, pp. 61-76, 2011.

[16] L. Wang, "The essence of grain financialization and countermeasures," Academic Journal of Zhongzhou, vol. 1, pp. 45-47, 2014.

\section{Acknowledgments}

This work was supported by "Exchange Program of the University of International Business and Economics;" "Research on the Impact of Industrial Agglomeration on Regional Economic Innovation and Development--Based on the Empirical Analysis of Economic Integration in the 